and pneumonia, that continue to kill millions. Meanwhile, even if global HIV transmission comes to a complete halt tomorrow, bills for the treatment of those who are currently infected will keep coming in and will need to be paid for decades by governments, donors, family members or patients themselves. Prevention efforts continue to make economic and humanitarian sense: an infection prevented today equals a lifetime of medical costs saved.

Unimagined Community shows how "social butterflies" and "open skies" are equally important for the transmission of HIV. The transmission networks are sustained by highly mobile infected people who change their sexual partners frequently. Thornton makes a strong case for uncovering the social factors that power these networks, and for developing new prevention efforts to counter them. Sex is a social act, not just a behaviour, so it follows that social interventions are necessary to curb the flow of infection.
The failure of $\mathrm{ABC}$ messages - "Abstain, Be faithful, use Condoms if you must graze" - to interrupt HIV transmission must be viewed in the light of Thornton's study. Sexual networks need to be understood and targeted alongside individual behaviour change. It is time to recruit anthropologists with the training and experience to carry out a professional analysis.

Karunesh Tuli is a public-health consultant based in Pasadena, California.

e-mail: karuneshtuli@hotmail.com

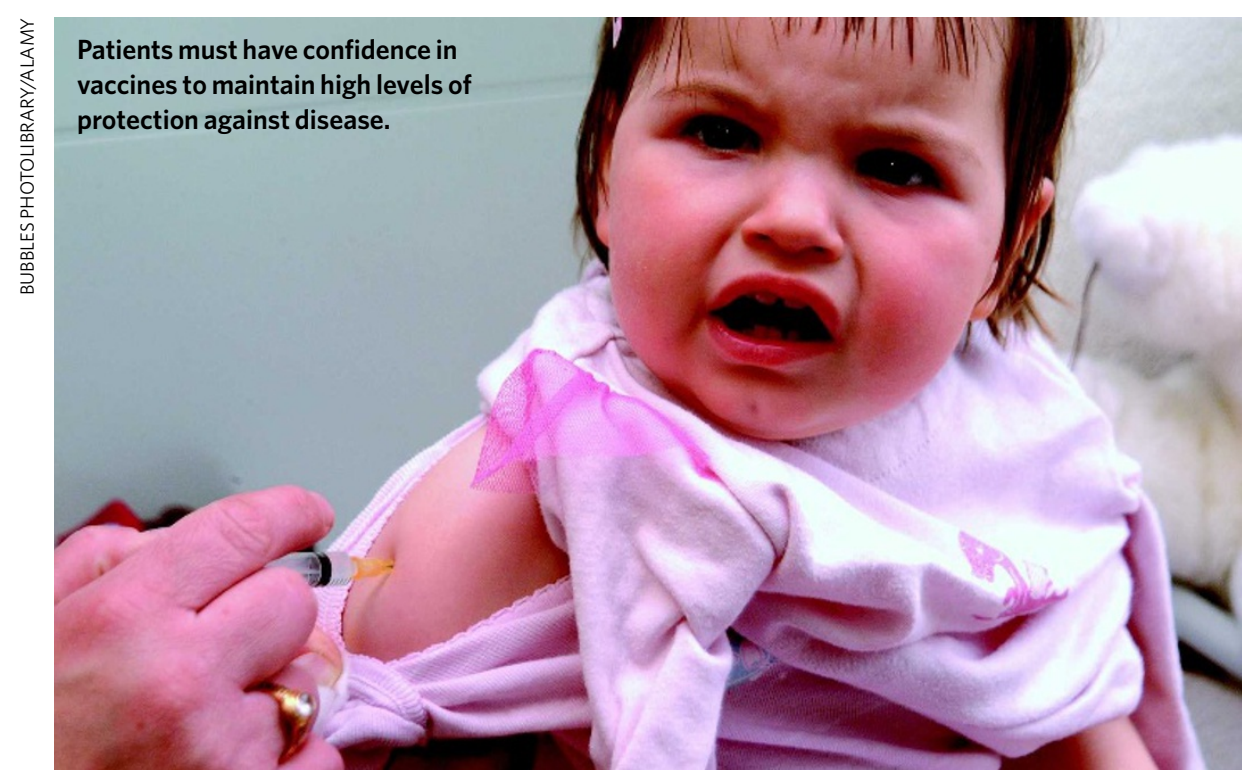

\title{
Injecting trust into vaccines
}

\section{Autism's False Prophets: Bad Science, Risky Medicine, and the Search for a Cure by Paul A. Offit \\ Columbia University Press: 2008. 328 pp. $\$ 24.95, £ 14.95$}

Paul Offit's distinguished academic credentials and long-standing advocacy for vaccines in the United States provide the weight behind this forceful book. Autism's False Prophets focuses on the people and events in that country that were central to the claimed link between vaccination and autism. Written with passion, authority, bluntness and literary skill, it largely lives up to the back cover's promise of a 'page-turner.'

The text is rich in heroes and villains. The villains include litigious parents, publicityseeking journalists, politicians, lawyers and environmental activists, lobbyists and expert witnesses. An assortment of quacks, zealots and incompetents, frequently from within the medical or allied professions, complete the roll-call of 'false prophets'. No wonder the public struggles to use good science as the sole arbiter for rational behaviour.

Offit does not underestimate the emotional and financial strains on parents whose children have autism, their compulsion to apportion responsibility for presumed damage, or their rich and positive experiences with their autistic offspring. He is sympathetic to parents who, impatient with the "glacial pace of medical research", all too often succumb to fashionable cures that fail to deliver. He dismisses the 300 or so US physicians who practice alternative and sometimes damaging 'remedies' for autism as "a cottage industry of false hope".

Two chapters cover the measles, mumps and rubella (MMR) vaccine controversy in the United Kingdom. In 1998, physician Andrew Wakefield published a highly flawed study in The Lancet proposing a link' between the MMR vaccine and autism. At a preceding press conference, he advocated the separation of MMR into three vaccines until the issue of safety was 'resolved'. Offit lays bare the weaknesses of Wakefield's discredited assertions and the questionable ethical practices associated with his work as a physician. Offit also covers the extensive, often uncritical reporting of Wakefield's view by the UK press, which collectively promoted the unwarranted public anxiety still responsible for the dangerously diminished uptake of the MMR vaccine in the United Kingdom.

Later chapters tell the tale of the mercurycontaining compound thimerosal, used since the 1940s as an effective, convenient vaccine preservative. By the late 1990s, some vaccine scientists in the United States were calling for the precautionary abandonment of thimerosal. They feared the rare possibility of subtle neurological and psychological effects from the preservative, although evidence is negligible. In 1999, the US vaccine authorities announced the removal of thimerosal from vaccines, using tortuous sentiments to reassure: "The current levels of thimerosal will not hurt children, but reducing those levels will make safe vaccines even safer." In a chapter entitled 'Mercury Rising', Offit vividly describes how such weasel words opened the floodgates of public concern. Here, he misses an opportunity for international comparisons of scientific and public attitudes - thimerosal anxiety was mainly a US fixation, even though the same preservative was used in the United Kingdom and other countries.

Public belief that vaccines cause autism soon escalated, fuelled by environmentalists, lawyers, politicians and opportunistic scientists publishing in journals of mixed repute. The chapter 'Mercury Falling' describes how the accumulating scientific evidence, from more than 200 epidemiological and other analyses, led scientists to refute the notion that thimerosal causes autism. A major factor was that even after the abandonment of thimerosal, rates of autism continued to increase. Over time, the preservative was exonerated to the satisfaction of most critics.

In bemoaning today's withdrawal of trust 
from medical professionals, Offit risks overegging his case for science. Precaution is sometimes a wise basis for policy-making. Vaccine damage through unforeseen effects does occasionally occur and may be severe. As Offit reminds us, one in every 100,000 patients suffered paralysis as a consequence of the US swine flu vaccination in 1976. Such rare episodes do not detract from the transformational effect of vaccines. But they remind us that not all concerns about vaccines can be dismissed as irrational.

Offit reports the personal testimonies of caring parents to good effect, but despairs in equal measure about their lack of scientific credibility and strong emotional appeal. One celebrity mother of an autistic child said, for example, "My science is Evan, and he's at home." Offit is anxious about patients actively participating in their own medical care using the Internet. For him, scientifically sound information online is drowned by poorly substantiated opinion.

Yet Offit's arguments falter when he uses vaccine controversies as his indicator of the presumed ignorance of science by the public. Communicating risk is notoriously tricky. Vaccine uptake needs to be sufficiently high to ensure protection of the population through 'herd immunity' - a persuasive task made all the more difficult when individual patients are urged to accept responsibility for their health and embrace the principle of choosing a hospital or consultant.

Autism's False Prophets encapsulates the fanciful belief among scientists, not supported by those who research science communication, that understanding the science will inevitably tip the scales of public opinion. This stance was demonstrated earlier this year in a letter to The Guardian newspaper from David Salisbury, director of immunization at the UK Department of Health. It draws attention to the ongoing UK public information campaign for adopting a vaccine intended to protect young women from human papilloma virus, the cause of most cervical cancer. The campaign, Salisbury wrote, aims to ensure that "parents and young women have all the information they need to consent to this important vaccine". Absent in such sentiments is a belief in the necessity for dialogue with the public, entirely different in tone and purpose from the mistaken compulsion of some well-intentioned vaccine enthusiasts to inject hard facts into empty vessels.

Jeff Thomas teaches science communication and health sciences in the Department of Life Sciences at The Open University, Milton Keynes, MK7 6AA, UK. He is co-editor of Practising Science Communication in the Information Age. e-mail:j.n.thomas@open.ac.uk

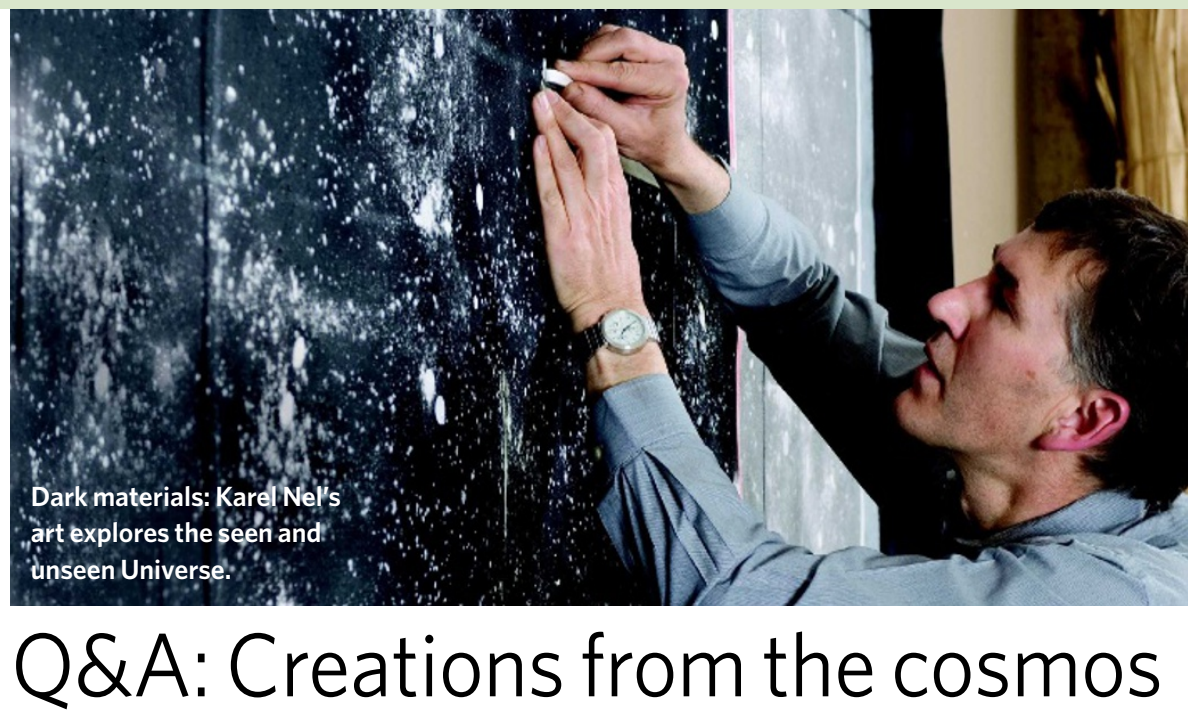

Artist Karel Nel works with astronomers from COSMOS, the global Cosmic Evolution Survey that is mapping galaxies and dark matter. Now exhibiting his work in London, he tells Nature how his view of the Universe has changed.

How did you get involved in astronomy?

Artists and scientists have questioned the nature of reality for centuries. Feeling the need to grasp contemporary scientific paradigms, I had worked for decades at the interface between these disciplines when I met Nick Scoville, leader of the COSMOS project. He invited me to be its resident artist. It was a very steep learning curve: I felt like an ant being taught compound interest by an economist.

\section{What does your work convey?}

My art investigates seen and unseen worlds. COSMOS looks back in deep time at patterns of galaxy formation and largescale structures, and from these, attempts to understand invisible dark energy and dark matter. I use metaphorical means to grasp these abstract ideas, as scientists often do. In my 20 exhibited works, I use mixed media including 540-million-year-old black carboniferous dust and white primordial salts from the oceans to present shimmering images of galaxies that emitted their light millions of years ago.

Have the scientists influenced your ideas? Yes - representing the Universe is not like painting a traditional landscape; there are invisible as well as visible aspects to convey. Scientists have developed codes to deal with cosmic phenomena, and my work captures the unstable nature of our perceptions of this distant, unknown terrain. In one piece, dotted lines echo the grids found in astronomy textbooks, but also refer to invisible characters, as used in comic books. In another, I evoke the 'blind spots' of telescopes with amorphous dark shapes.

\section{Did you influence the astronomers?}

Many of the astronomers focus on incremental, detailed information, so my broad outsider's perception rekindled the extraordinariness of their endeavour.

What was it like, visiting observatories?

At the summit of Mauna Kea, Hawaii, some of the world's most powerful telescopes are trained on the powder-black darkness, looking at complexity and eternity. It is awesome and desolate. Even the scientists fall silent in the face of that.

Interview by Jennifer Rohn, a researcher at University College London, Gower Street, London WC1E 6BT, UK, and editor of www.lablit.com. e-mail: jenny@lablit.com

\section{The Brilliance of Darkness}

Art First, 9 Cork Street, London W1S 3LL Until 9 October 2008

\section{Enhance your life with Nature debates}

Nature has picked two panels of experts in science, policy and ethics to debate research that is improving mental and physical abilities.

Enhancing the Brain: 13 October 2008 From intelligence to emotional tolerance, sleep requirements and memory power, how are developments in neuroscience affecting the individual and society? Panel: Barbara Sahakian, John Harris and Nick Bostrom.
Enhancing the Body: 10 November 2008 Studies of the human body are focusing on aspects such as speed, strength and healing or the tolerance of pain. But how will this science enhance the human body? Panel: Aubrey de Grey, Andy Miah and Kevin Warwick.

Nature debates will be held at 7pm at King Place, 90 York Way, London N1 9AG, UK See http://tinyurl.com/4zrh8v for more details. 